\title{
色彩イメージスケールの計測的表現に関する試み
}

\author{
奈良佐保女学院短期大学 中村 妙子・佐々木泰子 \\ 東大阪短期大学 佐藤 哲也 \\ 宝塚造形芸術大学 寺主一成
}

\section{AN ATTEMPT FOR INSTRUMENTAL EXPRESSION OF THE COLOR IMAGE SCALE}

\author{
Taeko Nakamura*1, Yasuko Sasaki*1, Tetsuya Sato ${ }^{* 2}$, and Kazushige Teraji ${ }^{* 3}$ \\ *1 Nara Saho Junior Women's College, Rokuyaoncho, Nara, 630 Japan \\ *2 Higashiosaka Junior College, Higashiosaka, Osaka, 577 Japan \\ *3 Takarazuka University of Art \& Design, Takarazuka, Hyogo, 665 Japan
}

\begin{abstract}
In order to study whether it is possible to express color images instrumentally, a color image scale for the determination of a chromaticity point by colorimetry was considered. The color image scale was divided into several color image regions by assigning the chromaticity point of each color chart to the color image of a color chart, on the color image scale. The chromaticity point and the color image can effec tively be determined using the relationship between the chromaticity point and the color image in the color image scale.
\end{abstract}

(Received November 28, 1990)

\section{1. 粕 言}

テキスタイルの分野においては，最近，機能性よりも ファッション性を重要視する傾向にあり，形や，材質な どよりもカラー，特に配色をいかにするかが大きな問題 となってきたここ数年、配色関係の成書などがよく刊 行されるようになってきており，その多くは色を定性的 に取り扱っている。李た、コンピュタ・グラフィック 機器の発達が著しく，配色への活用なども期待されてい るが，色材で表現できる物体色とカラーブラウン管上に

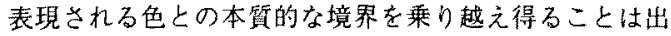
来ない。

配色イメージは最終的には個人の感性に依存するとこ ろが大であるが、このように配色がクローズアップきれ てきた状沉を考えると，若干でも前進した定量的手法が 是非とも必要とされる段階に来たように思われる。本報 では，そのような定量的手法への手がかりを得るための 1 つの試みとして計測的な色彩イメージスケールを提案 しだそのイメージスケール上で具体的な色票の色度点 とその色票のもつ視感的な力ラーイメージをを対応さ せ，色彩イメージスケールをいくつかのカラーイメージ
領域に区分し、より有効に利用できるようなスケールと した。

\section{2. 色の見元区分域の定量的分割}

色は，色相，明度，彩度の3つの属性から成り立って おり，その 3 属性に基ついた表色系の1つにMunsell 表 色系がある。この Munsell 表色系は、䋖部の点ではいく らかの異論があるものの，全体的には視感との対応に倲 れており，また測色值から精度よく変換できるので，広 く有効に利用されている。しかし，奏際の配色を行う際 に，この3 属性に基ついてイメージを構成することは必 ずしも現実的な手法ではない。そこで，例えば，わが国 の PCCS 表色系などでは明度と彩度とを組み合わせた， いわゆる“トーン”という概念を考え，色相とトーンの 2 要素で考えるのが適当であるとしている。このトーン 汁，“明度上彩度による色の調子の別”上定義されてお り，明度と彩度で構成される色相平面をいくつかのト一 ン領域に区分当れている。このトーン区分を行う場合， PCCS 表色系は，純色の彩度は等価值に見なしている が，純色の明度は等価值に見なしていないため，同じト ーンであっても色相によって明度が異なり，明度水漼で 
トーンを分割することはできない。例えば，黄色の vividトーンは, 明度が高いが, 青色の vivid トーン は，明度が低いため，vividトーンを一定の明度線で分 割することは困難である。

そこで著者の1人である寺主は，配色イメージ構成に おいて，明度の属性が必ずしも有效な尺度ではなく，色 の濃さの尺度が重要であると考え，これまでの色相と明 度と彩度の属性ではなく，色相之色濃度と彩度(あるい は鮮明度)の組合せによって色を解析すべきであるとし た。色濃度と彩度，または色濃度と鮮明度の組合せを用 いることによって，色相にかかわりなく一定の色潾度レ ベルでトーン区分することが可能となった。この色濃度 值の算出法は，いくつかの型が考えられるが, 色濃度指 数と呼んでいる方式では，次式のように， $\mathrm{D}_{\mathrm{L}}^{*}$ 値として 算出される[1）。これは0-100範囲の值をとるように なっている。

$$
\begin{aligned}
& \mathrm{D}_{\mathrm{L}}^{*}=(10-\mathrm{V})+\frac{2 \mathrm{C}\left(\mathrm{m}+\mathrm{H}_{5 \mathrm{P}}\right) \times 10^{-3}}{\log 2} \\
& \mathrm{~V}: \text { マンセル明度 } \quad \mathrm{C}: \text { マ: } \text { マレル彩度 }
\end{aligned}
$$

$\Delta \mathrm{H}_{5 \mathrm{P}}$ ：マンセル色相環(100分割)における5P加らの Hue $\operatorname{step}\left(0 \leqq \Delta \mathrm{H}_{5 \mathrm{P}} \leqq 50\right)$

式 1 中の $\mathrm{m}$ は，色域の大きさを決定する定数であっ て，通常の物体色については， $\mathrm{m}=5$ として計算するこ とによって、ほとんどすべての物体色をその色域内に収 容することができる。

この色漶度指数 $\mathrm{D}_{\mathrm{L}}^{*}$ とマンセル彩度 $\mathrm{C}$ とを組み合わせ たものをカラースコア(COLOR SCORE)と㭔んでいる が,このカラースコアは図 1 に見るような直角三角形と

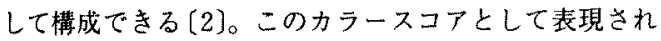
た色相三角形は，ほとんどすべてのマンセル色相平面の 色域を满たしている。カラースコア上に示されたトーン 区分は，ISCC-NBS色名区分図と照合してみて，色相に かかわりなくかなり良好な一致が得られる[3]。したが って、このカラースコアを用いることによって、いわゆ るトーン区分を測色学的に取り扱うことができ，“色の 見之”を定量的に扱うことが可能であると考えられる。

またこの色相三角形では，無彩色軸を構成する縦軸の 頂点(白色点)から，最高色濃度值 $\left(\mathrm{D}_{\mathrm{L}}^{*}=10\right)$ を持つ底辺 の各点を結ふ图 2 のうな直線によって色の鮮やかさを 表現し、この直線は次のような鮮明度指数值 $(\mathrm{Br})$ とし て数值的に表すことができる $[4] 。$

$$
\mathrm{Br}=\frac{10 \mathrm{C}}{2.509 \mathrm{D}_{\mathrm{L}}^{*}}
$$

定数2.509は， $\mathrm{D}_{\mathrm{L}}^{*}$ の郡算式において， $\mathrm{m}=5$ と設定し たときにマンセル彩度の最高值が $\mathrm{C}_{\text {max }}=25.09$ となるこ とに基づくものである。すなわち， $\mathrm{D}_{\mathrm{L}}^{*}=10, \mathrm{C}_{\max }=$

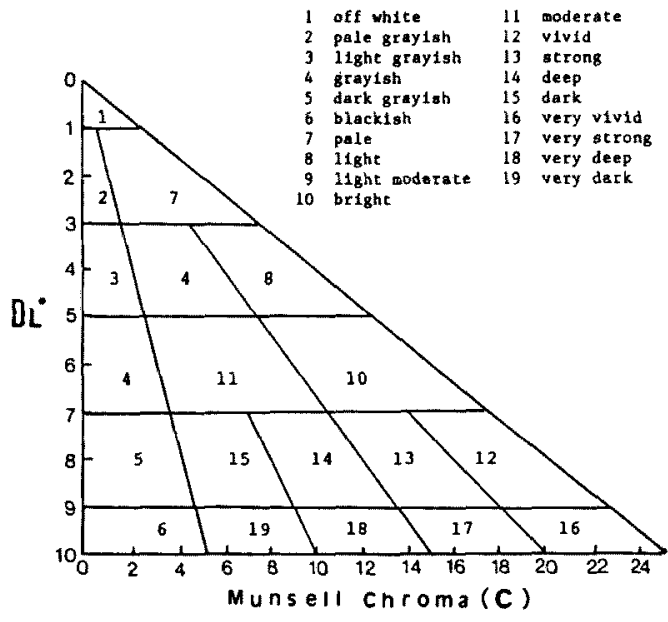

Fig. 1. Color score composed of $D_{L}^{*}$ and $C$.

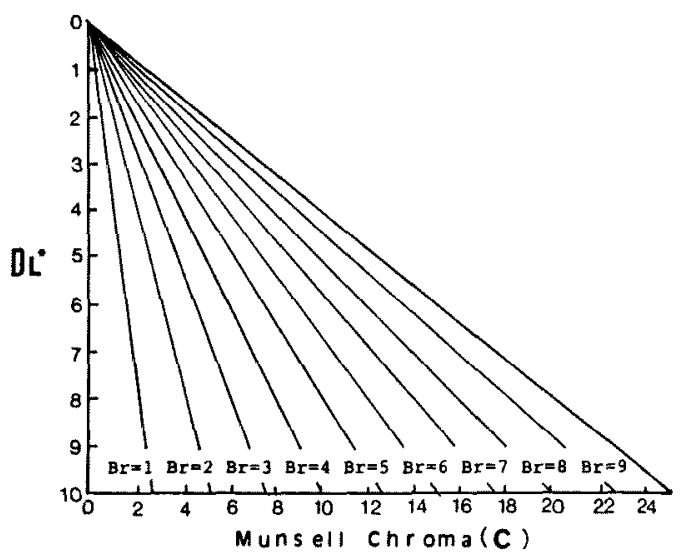

Fig. 2. Br line in the color score

25.090 とき $\mathrm{Br}=10$ となるので，この色相三角形では斜 边がもっとも鮮やかな色を連㹱る楾となり，無彩色軸に 対応する箱軸 $\mathrm{Br}=0$ がもっとも鮮やかさの小さい色の 集合ということになる。すなわち，色の鮮やかるは，0 一10での範井を持つ指数値として表現できる。

\section{3. 計測的色彩イメージスケールの基本粠成}

Kobayashi [5] は, warm-cool, soft-hard, clear-gray ishを3つの基本軸としたイメージスケールを提案し, イメージ配色を warm-cool, soft-hard 2 基本軸とし た平面上で取り扱っている。そのイメージスケール上に 色㸷を配置する際，各トーンごとに色相の異なる10種の 色票の色度点が示されているので，それを目安として色 度点を決めなければならない。よって，イメージスケー 
Table 1 Degree of Warmth and Coolness for Each HV/C (Chiziiwa Data (6))

\begin{tabular}{|c|c|c|c|c|c|c|c|c|c|c|c|c|c|}
\hline H. V.C & & & & $\mathrm{ol}+$ & - & $\ldots$ & - & - & $\rightarrow w$ & & & & \\
\hline $5 \mathrm{R}$ & & & & & & $2 / 2$ & $\begin{array}{l}4 / 4 \\
4 / 2\end{array}$ & $\begin{array}{l}8 / 2 \\
4 / 6\end{array}$ & $\begin{array}{l}6 / 4 \\
6 / 6\end{array}$ & $4 / 8$ & $\begin{array}{l}4 / 10 \\
6 / 8\end{array}$ & $\begin{array}{l}4 / 12 \\
4 / 10\end{array}$ & $5 / 12$ \\
\hline 5YR & & & & & & & $\begin{array}{l}8 / 2 \\
6 / 2 \\
4 / 2\end{array}$ & $\begin{array}{l}4 / 4 \\
4 / 6 \\
6 / 4\end{array}$ & & $\begin{array}{l}8 / 4 \\
6 / 8\end{array}$ & $8 / 6$ & $8 / 10$ & $7 / 14$ \\
\hline $5 Y$ & & & & & $\begin{array}{l}4 / 2 \\
6 / 2\end{array}$ & & $\begin{array}{l}6 / 4 \\
4 / 4\end{array}$ & $\begin{array}{l}6 / 6 \\
8 / 2 \\
6 / 8\end{array}$ & $8 / 4$ & & $\begin{array}{l}8 / 6 \\
8 / 8\end{array}$ & & $8 / 12$ \\
\hline $5 G Y$ & & & & & $\begin{array}{l}4 / 2 \\
6 / 2\end{array}$ & $\begin{array}{l}6 / 4 \\
8 / 2\end{array}$ & $\begin{array}{l}6 / 6 \\
8 / 6 \\
8 / 4\end{array}$ & $\begin{array}{l}6 / 8 \\
7 / 10\end{array}$ & $\begin{array}{l}8 / 10 \\
8 / 8\end{array}$ & & & & \\
\hline $5 G$ & & & & & $\begin{array}{l}4 / 2 \\
4 / 4 \\
6 / 2 \\
8 / 2\end{array}$ & $\begin{array}{l}4 / 6 \\
5 / 8 \\
8 / 4 \\
6 / 4\end{array}$ & $\begin{array}{l}7 / 8 \\
6 / 8 \\
6 / 6\end{array}$ & & & & & & \\
\hline $5 B G$ & & & $\begin{array}{l}4 / 2 \\
4 / 6 \\
2 / 2 \\
6 / 2 \\
6 / 6\end{array}$ & $\begin{array}{l}8 / 2 \\
5 / 8\end{array}$ & $\begin{array}{l}6 / 6 \\
6 / 8 \\
8 / 4\end{array}$ & & & & & & & & \\
\hline $5 B$ & $\begin{array}{l}4 / 6 \\
6 / 4\end{array}$ & $\begin{array}{l}4 / 4 \\
4 / 8 \\
6 / 8\end{array}$ & $\begin{array}{l}4 / 2 \\
6 / 6 \\
8 / 2 \\
8 / 4\end{array}$ & & & & & & & & & & \\
\hline $5 \mathrm{~PB}$ & & $\begin{array}{l}4 / 2 \\
4 / 6 \\
4 / 10 \\
6 / 6\end{array}$ & $\begin{array}{l}6 / 4 \\
6 / 8 \\
8 / 2\end{array}$ & $\begin{array}{l}4 / 12 \\
6 / 2\end{array}$ & & & & & & & & & \\
\hline $5 P$ & & & & $\begin{array}{l}4 / 2 \\
4 / 4 \\
8 / 2\end{array}$ & $\begin{array}{l}4 / 6 \\
4 / 8 \\
6 / 4\end{array}$ & $\begin{array}{l}4 / 10 \\
4 / 12 \\
6 / 2\end{array}$ & $6 / 8$ & $6 / 6$ & & & & & \\
\hline $5 R P$ & & & & $4 / 2$ & $6 / 2$ & & $\begin{array}{l}4 / 4 \\
4 / 6 \\
6 / 4\end{array}$ & $8 / 2$ & & $\begin{array}{l}4 / 8 \\
4 / 10 \\
6 / 6 \\
8 / 4\end{array}$ & $\begin{array}{l}4 / 12 \\
4 / 12 \\
6 / 8\end{array}$ & & \\
\hline
\end{tabular}

ルを䁚色值に基ついた定量的なものにするためには，定 量化できる基本軸を選ぶ必要がある。そこで，先に述べ たカラースコア図をイメージスケールとして応用するこ とを試みた。

カラースコア图は、色相平西色漊度と彩度とで表す ものであって，色相因子は念まれていない。したがっ て，これをすべての色を詨象とするイメージスケールと して用いられるるうにするためには，新たに色相因子す
るいはそれに代わるものを加昧しなければならない。 ちろんカラースコア図を色濃度軸を中心として360度回 転させて構成できる円錐色立体を用いれば，すべての色 相が取り扱えることはいうまでもないが，配色という奏 用的な目的のためのイメージスケールとしては，立体で なく平面因として構成する方が感覚的にも理解し易く。 きたより害用的なものになると考えられる。

色相を大く分類する方法の1つとして，寒色おる 

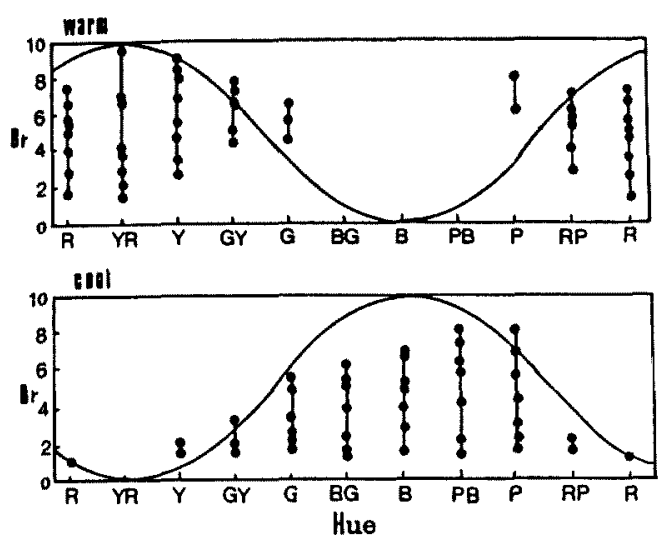

Fig. 3. Relationship between Hue and $\mathrm{Br}$ value led from Table 1.

いは冷色)と暖色という組合せがある。もちろん, 寒色 とか暖色という区分は，色相属性のもつすべての性質を 表しているものではないが，色相のちがいを大きく区分 できる尺度であることは確かである。しかもそれを前述 のカラースコア図と重格わせて平面化した尺度として 表現しようとするためには，適当な簡便さを持つ尺度で あると考えられる。

\section{4. 色彩イメージ彩度の表現法}

たとえば，千々䂟ら（6] は寒色および暖色に関する 色彩心理実験の結果を表 1 のように発表しておりここの 表からおよその傾向はとらえることができる。ただし， この表の定量的な読み方は示されていない。そこで,こ の表に示された表色値を先に述べた鮮明度指数 $\mathrm{Br}$ に変 換して色相軸に対してプロットしてみると，図 3 が得ら れた。5YR色相抢よび $5 \mathrm{~B}$ 色相が寒暖イメージの最大色
Table $2 M_{W}$ Value and $M_{C}$ Value for Each Hue

\begin{tabular}{lcc}
\hline Hue & $\mathrm{M}_{\mathrm{W}}$ & $\mathrm{M}_{\mathrm{C}}$ \\
\hline $5 \mathrm{R}$ & 0.905 & 0.095 \\
$5 \mathrm{YR}$ & 1.000 & 0.000 \\
$5 \mathrm{Y}$ & 0.905 & 0.095 \\
$5 \mathrm{GY}$ & 0.655 & 0.345 \\
$5 \mathrm{G}$ & 0.345 & 0.655 \\
$5 \mathrm{BG}$ & 0.095 & 0.905 \\
$5 \mathrm{~B}$ & 0.000 & 1.000 \\
$5 \mathrm{~PB}$ & 0.095 & 0.905 \\
$5 \mathrm{P}$ & 0.345 & 0.655 \\
$5 \mathrm{RP}$ & 0.655 & 0.345 \\
\hline
\end{tabular}

相となりそれれの色相から渐次的に変移し，その変移 は図3に示したように余弦曲線として表現される。しか し，図3からわかるように，同じ色相であっても色濃度 や鮮明度が異なれば，暖色と寒色との間の変換が起こ。 ており,その余弦曲楾は色相の持つ暖色度あるいは寒色 度の鮮明度域を示すと解釈することができる。したがっ て，図 3 に示されたデータから，次のような暖色度指数 $\left(\mathrm{M}_{\mathrm{W}}\right)$ あるいは寒色度指数 $\left(\mathrm{M}_{\mathrm{C}}\right)$ 竞導くことができると考 えられる。

$$
\begin{aligned}
& \mathrm{M}_{W}=0.5\left[1+\cos \left(3.6^{\circ} \times \Delta \mathrm{H}_{5 Y R}\right)\right] \\
& \mathrm{M}_{\mathrm{C}}=0.5\left[1+\cos \left(3.6^{\circ} \times \Delta \mathrm{H}_{5 \mathrm{~B}}\right)\right]
\end{aligned}
$$

ここで， $\Delta \mathrm{H}_{5 \mathrm{YR}}$ および $\mathrm{H}_{5 \mathrm{~B}}$ は，それぞれ100等分マン 七ル色相環上に扮ける色相 $5 \mathrm{YR}$ および5Bからの色相ス テップで，0-50の範囲の值をとるものである。

暖色度指数 $\left(\mathrm{M}_{\mathrm{W}}\right)$ と寒色度指数 $\left(\mathrm{M}_{\mathrm{C}}\right)$ の関係は表 2 に見 るように相互に表弿の関係にあたるので，どちらか一方 だけの表示で十分である。

この $\mathrm{M}_{\mathrm{W}}$ 值あるいは $\mathrm{M}_{\mathrm{C}}$ 值は，それぞれの色相に招け る鮮明度域と色相の与える寒暖イメージとの兼权合いを

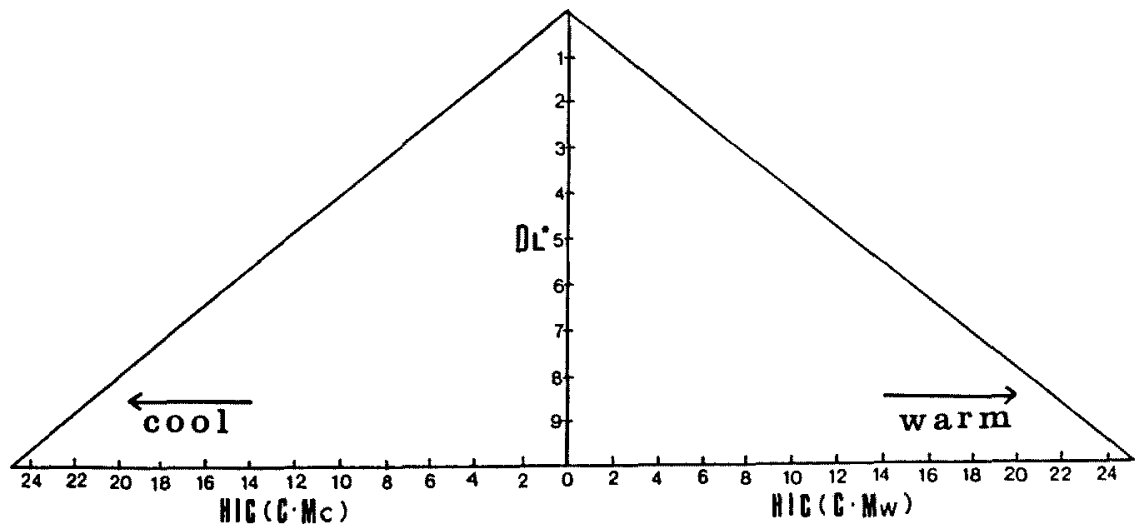

Fig. 4. Color image scale composed of $D_{L}^{*}$ and $\mathrm{HIC}$. 


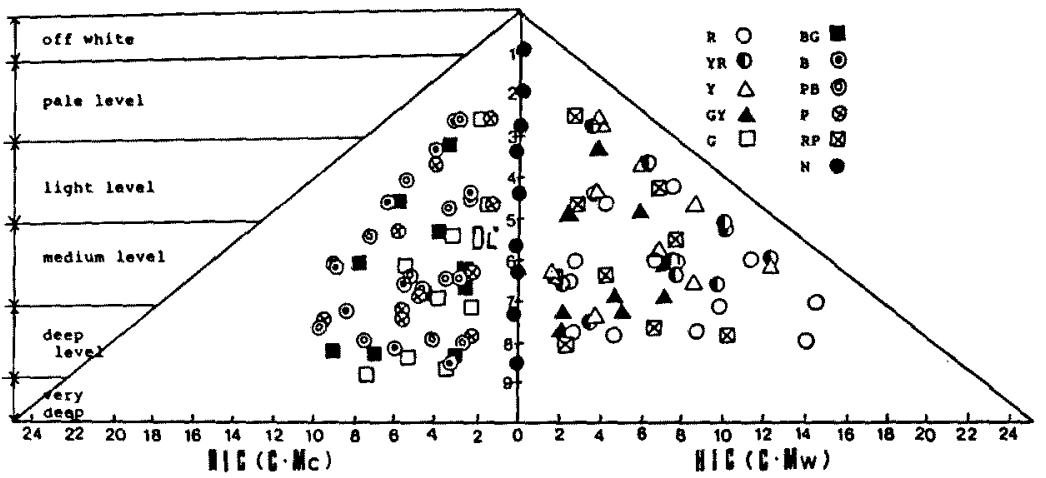

Fig. 5. Plotted color chart in the color image scale.

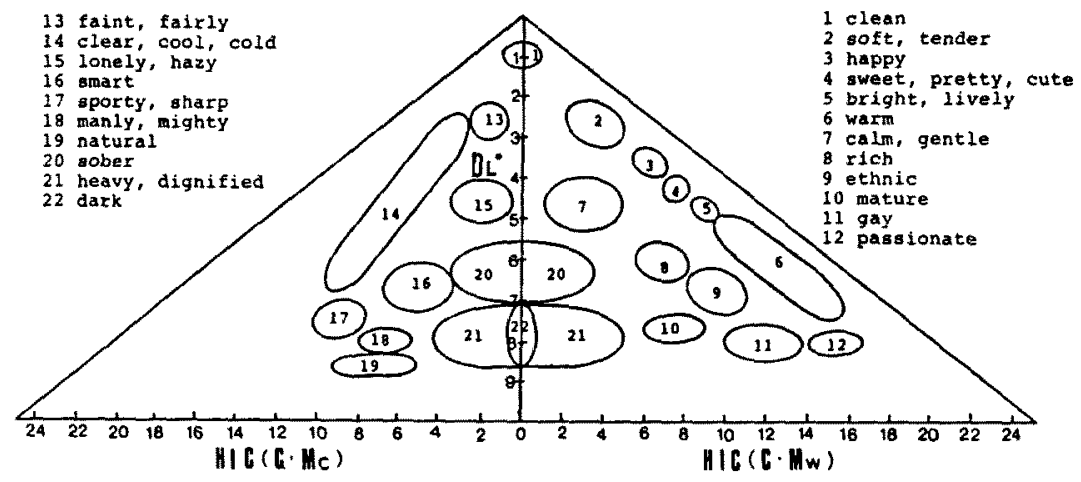

Fig. 6. Image regions in the color image scale.

示していると考えられるので，色相ごとのイメージの違 いを考慮していない通常のマンセルクロマCにこの指 数を乗じたC・政あるいは $C \cdot M_{C}$ あ，色柏因子を加味し た一種の色相イメージ彩度 (Hue Image Chroma 頭文字を 取って HIC と呼称する)と見なすことができる。

すでに触れたようにここで考慮される色相因子は寒 暖関係だけであるが，寒暖イメージが色相イメージのも っとも重要なものの1つであるとすれば，先のカラース コア図と重ね合わせるべき色相イメージの平面化した表 現形式として，1つの有効な指標とすることができると 思わ机る。

カラースコアと色相イメージ彩度を重权合わせた色彩 イメージスケールは，暖色側と寒色側とをそれぞれ表現 する色相三角形を，無彩色の上ころで連結した二等辺三 角形として表現されることになる(图 4 )。すなわち，緱 軸は色濃度 $\mathrm{D}_{\mathrm{L}}^{*}$, 横軸は HICで構成される色彩イメージ スケールとなる。

\section{5. 計測的色彩イメージスケールと 心理実験との対応}

計測的な色彩イメージスケールの1つの試みが用意で きたのでここのスケール表現する色域二等边三角形上 入，具体的な色票の色度点を割り付けてみた。

試料として用いたのは，日本色彩研究所編の配色カ一 ド129である。この129色のうち, 公称 vivid卜ーン域た けにあって，その他のトーン域には存在しない12色を除 いた117色をC 光源 $2 \circ$ 視野の条件で測色し，そ机を色城 二等辺三角形上に割り付けしたのが图 5 である。

またこれらの色票群については, 別途に20才前後の 女子短大生100名に，表 3 のように用意した129種類の色 彩イメージ語との対応を求めた。すなわち，100名の铕

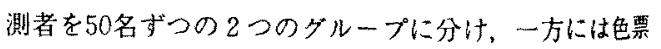
に対するイメージ語を1つずつ選ばせ，また他方にはイ メージ語に対する色票を1つずつ選ばせた。色票とイメ 一ジ語との対応関係は，必ずしも完全に一致した結果が 得られたわけではなく、ことに, 彩度が低くて無彩色に 近い色では，色相イメージも弱くなるので，イメージ語 との対応もつけ難いようであっだ。しかし，彩度の高 い, したがって，色相イメージも明確で強い色について は，ほほ良好な対応性が認められた。またイメー語 
Table 3 Image words.

\begin{tabular}{|c|c|c|}
\hline 1 sweet & 2 warm & 3 stable \\
\hline 4 moderate & 5 calm & 6 adult \\
\hline 7 stylish & 8 elegant & 9 joyful \\
\hline 10 bright & 11 vivid & 12 gentle \\
\hline 13 lovely & 14 heavy & 15 solemn \\
\hline 16 mature & 17 active & 18 innocent \\
\hline 19 fine & 20 hot & 21 fashionable \\
\hline 22 gloomy & 23 ripe & 24 energetic \\
\hline 25 safety & 26 exotic & 27 ecology \\
\hline 28 ethnic & 29 cute & 30 healthy \\
\hline 31 happy & 32 easy & 33 lively \\
\hline 34 rhythmical & 35 casual & 36 charming \\
\hline 37 hazy & 38 light & 39 dark \\
\hline 40 rich & 41 classical & 42 gaudious \\
\hline 43 pungent & 44 clear & 45 pretty \\
\hline 46 country & $47 \mathrm{cool}$ & 48 high-grade \\
\hline 49 obedient & 50 sporty & 51 simple \\
\hline 52 natural & 53 sexy & 54 sharp \\
\hline 55 clarified & 56 quiet & 57 practical \\
\hline 58 soft & 59 clean & 60 statical \\
\hline 61 dignified & 62 refleshed & 63 new \\
\hline 64 artless & 65 refined & 66 sober \\
\hline 67 keen & 68 homely & 69 exciting \\
\hline $70 \mathrm{cool}$ climatic & 71 cloudless & 72 clearcut \\
\hline 73 cold & 74 positive & 75 negative \\
\hline 76 private & 77 noble & 78 smart \\
\hline 79 lonely & 80 chic & 81 solid \\
\hline 82 passionate & 83 feminine & 84 cheerful \\
\hline 85 delicate & 86 dramatic & 87 moving \\
\hline 88 chill & 89 dynamic & 90 urbane \\
\hline 91 powerful & 92 amorous & 93 manly \\
\hline 94 mighty & 95 inferior & 96 dandy \\
\hline 97 mild & 98 dull & 99 tranquil \\
\hline 100 graceful & 101 peaceful & 102 gay \\
\hline 103 distinct & 104 fresh & 105 violent \\
\hline 106 unpleasant & 107 flowery & 108 formal \\
\hline 109 punchy & 110 hard & 111 youthful \\
\hline 112 stirring & 113 romantic & 114 fairly \\
\hline 115 tender & 116 still & 117 young \\
\hline 118 weak & 119 intellectual & 120 fascinating \\
\hline 121 pleasant & 122 coolheaded & 123 modern \\
\hline 124 abundant & 125 merry & 126 serious \\
\hline 127 Japanese & 128 western & 129 faint \\
\hline
\end{tabular}

の中では，「暖かい」、「冷たい」などのようなその意味 にあいまいさのないものは色票と直線的に結びつけ易か ったようであるが,「クラシック」、「モダン」などの理 解の仕方にかなり個人的な差異のある用語はイメージそ
のものの混乱も認められた。

比較的に良好な対関係の認めら机た色票とイメージ語 との関係から, 図 5 に示した計測的色彩イメージスケー ル上の色度点にカラーイメージを対応させて割り付けて みたのが図 6 である。

\section{6. 結 言}

これまで，配色に関する尺度としては，定性的なイメ ージスケールしかなく，客観的な測色值と配色を結びつ けることはほとんど不可能であった。本報では，色濃度 と彩度によって表され，いわゆるトーン区分も定量出来 るカラースコア図を利用し，そこに warm および cool の程度を表示する尺度を色相因子として重ね合わせるこ とによって，配色のための感覚尺度を定量表示できるよ うなイメージスケールの構成を試みた。

さらにこのイメージスケール上では，それぞれの色 の色度点とその色の持つカラーイメージを重ねてとらえ ることができるので，色度点が決まればただちにカラー イメージをまたカラーイメージが決まればただちに色 度点を求めることが可能になるものと思われる。

今まで，マンセル表色系やオストワルト表色系におい て色彩感情との对応が検討されてきたが[7]，三属性が 複雑に関与しており，单純な形での対応はなるれていな い。しかしこの新たな色彩イメージスケールは，色 相，彩度，色濃度の3 属性を二等辺三角形上に展開する とともに，測色によりその色度点が決まるので，カラー イメージとの対応が簡単であり，感覚的に理解し易く，

より実用的に使用できるものと考える。

この定量化イメージスケールを，本当の意味で定量的 なものにするためには，さらに多くの心理実験的なデー タによる検証を加えていかなければならないと考えてい 万。

\section{文献}

1. 寺主一成, 宝塚造形芸術大学紀要，3，85（1989）

2. 寺主一成, 「色彩学基礎演習ノ一ト」, シースタ一色 彩研究所, p. 32 (1989)

3. 佐藤哲也, 寺主一成, 未発表

4. 寺主一成, 佐藤哲也, 宝场造形芸術大学紀要, 2 , 47 (1988)

5. Shigenobu Kobayashi: Color Research and ApplicaLion, 6, 93 (1981)

6. 千々岩英彰, 「色彩学」, 福村出版, 1983, p. 135

7. 色彩科学ハンドブック：日本色彩学会, 1982, p. 579 